\title{
Identification of gastric cancer risk markers that are informative in individuals with past $H$. pylori infection
}

\author{
Sohachi Nanjo $\cdot$ Kiyoshi Asada $\cdot$ Satoshi Yamashita $\cdot$ \\ Takeshi Nakajima $\cdot$ Kazuyuki Nakazawa $\cdot$ Takao Maekita $\cdot$ \\ Masao Ichinose $\cdot$ Toshiro Sugiyama $\cdot$ Toshikazu Ushijima
}

Received: 25 August 2011/Accepted: 26 November 2011/Published online: 12 January 2012

(C) The International Gastric Cancer Association and The Japanese Gastric Cancer Association 2011

\begin{abstract}
Background Epigenomic damage induced by Helicobacter pylori infection is accumulated in gastric mucosae before the development of malignancy. In individuals without current $H$. pylori infection, DNA methylation levels of specific $\mathrm{CpG}$ islands (CGIs) are associated with gastric cancer risk. Because risk estimation in individuals with past infection is clinically important, we here aimed to identify the risk markers that reflect epigenomic damage induced by $H$. pylori infection, and that are informative in these individuals.

Methods Gastric mucosae were obtained from 55 gastric cancer patients (GC-Pt) (21 with current infection and 34 with past infection) and 55 healthy volunteers (HV) $(7$ never-infected, 21 with current infection, and 27 with past infection). Hypermethylated CGIs were searched for by methylated DNA immunoprecipitation-CGI microarray,
\end{abstract}

Electronic supplementary material The online version of this article (doi:10.1007/s10120-011-0126-1) contains supplementary material, which is available to authorized users.

S. Nanjo $\cdot$ K. Asada $\cdot$ S. Yamashita $\cdot$ T. Ushijima $(\bowtie)$ Division of Epigenomics, National Cancer Center Research Institute, 5-1-1 Tsukiji, Chuo-ku, Tokyo 104-0045, Japan e-mail: tushijim@ncc.go.jp

S. Nanjo - T. Sugiyama

Third Department of Internal Medicine,

University of Toyama, Toyama, Japan

T. Nakajima

Gastrointestinal Endoscopy Division, National Cancer

Center Hospital, Tokyo, Japan

K. Nakazawa $\cdot$ T. Maekita $\cdot$ M. Ichinose

Second Department of Internal Medicine,

Wakayama Medical University, Wakayama, Japan and methylation levels were analyzed by quantitative methylation-specific polymerase chain reaction (PCR).

Results By microarray analysis of a pool of three samples from GC-Pt with past infection and another pool of samples from HV with past infection, 15 hypermethylated CGIs in the former pool were isolated. Seven of them had significantly higher methylation levels in GC-Pt with past infection $(n=10)$ than in HV with past infection $(n=10)$ $(P<0.001)$. In a validation cohort $(21 \mathrm{GC}-\mathrm{Pt}$ with past infection and $14 \mathrm{HV}$ with past infection), the seven new markers had large areas under the receiver-operating characteristic curves $(0.78-0.84)$ and high odds ratios (12.7-36.0) compared with two currently available markers $(0.60-0.65,5.0-5.7)$.

Conclusions We identified seven novel gastric cancer risk markers that are highly informative in individuals with past infection.

Keywords Carcinogenesis - DNA methylation . Gastric cancer · Helicobacter pylori

\section{Introduction}

Early detection of cancer is critically important to reduce its morbidity and mortality, and early detection can be achieved by identifying individuals at high risk of developing cancers. In the risk estimation of gastric cancers, a history of Helicobacter pylori infection, which increases gastric cancer risk 2.2- to 21-fold [1-4], plays the major role, but the vast majority of individuals with a history of H. pylori infection do not develop gastric cancers. Also, gene polymorphisms associated with gastric cancers have been identified, and they have been shown to confer odds ratios (ORs) mostly between 1.0 and 2.0 [5, 6]. To obtain 
clinically useful risk markers, we have to develop markers that are informative even in individuals with a history of $H$. pylori infection and that confer higher ORs.

Recently, we showed that $H$. pylori infection induces epigenomic damage, especially aberrant DNA methylation, in gastric mucosae [7]. DNA methylation levels of specific CpG islands (CGIs) were very high in the gastric mucosae of individuals with active $H$. pylori infection irrespective of gastric cancer risk, and decreased to certain levels after H. pylori was eradicated [8]. Importantly, these methylation levels in individuals without active $H$. pylori infection were correlated with gastric cancer risk [7, 9]. It is considered that aberrant DNA methylation is induced both in gastric stem cells and in non-stem cells, that methylation induced in stem cells will remain even after $H$. pylori eradication, and that methylation levels in individuals without current $H$. pylori infection reflect gastric cancer risk (degree of the epigenetic field defect) [10].

The correlation between methylation levels and gastric cancer risk has been analyzed in individuals without current $H$. pylori infection [7, 9]. Based on the data in our previous study [7], currently available methylation risk markers, $F L N C$ and THBD, have ORs of 4.2-7.0 to detect gastric cancer patients (GC-Pt) among such individuals. However, individuals without current $H$. pylori infection indeed consist of never-infected individuals and those with past infection, and risk estimation is important in individuals with past infection.

In this study, we aimed to identify gastric cancer risk markers that reflect epigenomic damage induced by $H$. pylori infection, and that are informative in individuals with past infection.

\section{Materials and methods}

Tissue samples and determination of $H$. pylori infection status

Fifty-five healthy volunteers (HV) with endoscopic findings of no malignancy were recruited, with written informed consents, on the occasion of a gastric cancer screening program, with the approval of the institutional review board. Fifty-five GC-Pt who had undergone curative endoscopic submucosal dissection (ESD) of a welldifferentiated adenocarcinoma in the non-cardia according to the Japanese classification of gastric carcinoma [11] were also recruited, with written informed consents, with the approval of the Institutional Review Board. Gastric mucosae were collected by endoscopic biopsy of the antrum. The biopsy specimens were frozen in liquid nitrogen immediately after biopsy, and stored at $-80^{\circ} \mathrm{C}$ until DNA extraction. High molecular weight DNA was extracted by the phenol/chloroform method.

Current $H$. pylori infection was analyzed by a serum antiH. pylori IgG antibody test (SRL, Tokyo, Japan) in HV and by urea breath test (Otsuka Pharmaceutical, Tokushima, Japan) in GC-Pt. Also, the presence of current or past H. pylori infection was detected by the endoscopic presence of atrophic gastritis in the antrum, because atrophic change induced by $H$. pylori infection arises in the antrum in $83 \%$ of individuals with $H$. pylori infection [12] and remains in all individuals who have had $H$. pylori eradication therapy [13]. "Never-infected individuals" were defined as those who were negative for $H$. pylori analysis and did not have atrophic gastritis in the antrum. "Individuals with current infection" were defined as those who were positive for $H$. pylori analysis. "Individuals with past infection" were defined as those who were negative for $H$. pylori analysis and had atrophic gastritis in the antrum.

Methylated DNA immunoprecipitation-CGI microarray analysis

Methylated DNA immunoprecipitation (MeDIP)-CGI microarray analysis was performed as previously described $[14,15]$. Briefly, $5 \mu \mathrm{g}$ of genomic DNA was immunoprecipitated with an anti-5-methylcytidine antibody (Diagnode, Liége, Belgium), and the precipitated DNA and the input DNA were labeled with cyanin (Cy) 5 and $\mathrm{Cy} 3$, respectively. A human CGI oligonucleotide microarray (Agilent Technologies, Santa Clara, CA, USA) was hybridized with the labeled probes and scanned with an Agilent G2565BA microarray scanner (Agilent Technologies). Scanned data were processed with Feature Extraction Software Version 9.1 (Agilent Technology) and Agilent G4477AA ChIP Analytics 1.3 software. The signal of a probe was converted into a "Me value", which represented the methylation level as a value from 0 (unmethylated) to 1 (methylated). Differentially methylated regions were detected by comparison between the Me values of two samples, and data were visualized in the UCSC Genome Browser (http://genome. ucsc.edu/) on NCBI36/hg18 assembly (National Center for Biotechnology Information, Bethesda, MD, USA).

Sodium bisulfite modification and quantitative methylation-specific polymerase chain reaction

Fully methylated DNA and fully unmethylated DNA were prepared by methylating genomic DNA with SssI methylase (New England Biolabs, Beverly, MA, USA) and by amplifying genomic DNA with the GenomiPhi amplification system (GE Healthcare, Buckinghamshire, UK), respectively. Bisulfite modification was performed using $1 \mu \mathrm{g}$ of BamHI-digested genomic DNA, and the modified 
DNA was suspended in $40 \mu \mathrm{l}$ of Tris-ethylenediamine tetraacetic acid (EDTA) buffer [16]. An aliquot of $2 \mu \mathrm{l}$ of sodium bisulfite-treated DNA was used in one reaction of quantitative methylation-specific polymerase chain reaction (PCR; qMSP).

qMSP was performed using primer sets specific to methylated and unmethylated sequences (Supplementary Table 1), SYBR ${ }^{\circledR}$ Green I (BioWhittaker Molecular Applications, Rockland, ME, USA), and an iCycler Thermal Cycler (Bio-Rad Laboratories, Hercules, CA, USA). The number of molecules in a sample was determined by comparing its amplification with those of standard DNA that contained known numbers of molecules $\left(10^{1}-10^{9}\right.$ molecules). Standard DNA was prepared by purifying the PCR products using the Wizard SV Gel and PCR Clean-Up System (Promega, Fitchburg, WI, USA). The methylation level was calculated as the fraction of methylated (M) molecules in the total number of DNA molecules (number of $\mathrm{M}$ molecules + number of unmethylated molecules). The percentage of methylated reference (PMR) was calculated as the fraction of the methylated reference $\{$ (number of $\mathrm{M}$ molecules in a sample)/(number of $\mathrm{Alu}$ repeat sequences in a sample) $\} /\{$ (number of $\mathrm{M}$ molecules in $S s s I$-treated DNA)/(number of $A l u$ repeat sequences in SssI-treated DNA) \} [17].

\section{Statistical analysis}

Differences in mean methylation levels or PMR were analyzed by the Student's $t$-test. The receiver-operating characteristic (ROC) curve was drawn, and the area under the curve (AUC) and OR were analyzed by binomial distribution and binomial logistic regression analysis, respectively. All the analysis was performed using PASW statistics (SPSS, Chicago, IL, USA), and the results were considered significant when $P$ values of less than 0.05 were obtained by two-sided tests.

\section{Results}

Isolation of hypermethylated CGIs in GC-Pt compared with $\mathrm{HV}$ in individuals with past $H$. pylori infection

A pool of three samples from HV with past infection and another pool of three samples from GC-Pt with past infection were analyzed by MeDIP-CGI microarray analysis. CGIs that were hypermethylated in the latter group compared with the former group were selected as follows: (1) Me value in the latter pool was higher than that in the former pool by 0.2 or more, (2) Me value in the former pool was lower than 0.4, and (3) criteria (1) and (2) were satisfied in three consecutive probes. A total of 15 CGIs were isolated by these criteria (Table 1), and representative data around CGI \#5 are shown in Fig. 1.

From the 15 CGIs, those differentially methylated in a screening set, which consisted of $10 \mathrm{HV}$ with past infection and 10 GC-Pt with past infection, were searched for by evaluating PMRs by qMSP (Supplementary Table 2). Seven CGIs (\#1 to \#7; Table 1), distributed on various chromosomes, were methylated at significantly higher

Table 1 CGIs identified by MeDIP-CGI microarray

\begin{tabular}{|c|c|c|c|c|}
\hline $\begin{array}{l}\text { CGI } \\
\text { no. }\end{array}$ & $\begin{array}{l}\text { Gene } \\
\text { symbol }\end{array}$ & Name & $\begin{array}{l}\text { Chromosomal } \\
\text { position }\end{array}$ & $\begin{array}{l}\text { Location } \\
\text { around a } \\
\text { gene }\end{array}$ \\
\hline$\# 1$ & $E M X 1$ & $\begin{array}{l}\text { Empty } \\
\text { spiracles, } \\
\text { homeobox } 1\end{array}$ & $2 \mathrm{p} 13.2$ & Intron 1 \\
\hline \#2 & $\operatorname{miR663}$ & MicroRNA 663 & $20 p 11.1$ & Overlap \\
\hline \#3 & $N K X 6-1$ & $\begin{array}{l}\text { NK6, } \\
\text { homeobox } 1\end{array}$ & $4 q 21.23$ & Intron 1 \\
\hline \#4 & OTP & $\begin{array}{l}\text { Orthopedia } \\
\text { homeobox }\end{array}$ & $5 q 13.3$ & Downstream \\
\hline \#5 & $O P L A H$ & $\begin{array}{l}\text { 5-Oxoprolinase } \\
\text { (ATP- } \\
\text { hydrolysing) }\end{array}$ & $8 \mathrm{q} 24.3$ & Downstream \\
\hline \#6 & $C Y P 1 B 1$ & $\begin{array}{l}\text { Cytochrome } \\
\text { P450, family } 1 \text {, } \\
\text { subfamily B, } \\
\text { polypeptide } 1\end{array}$ & $2 \mathrm{p} 22.2$ & Exon 1 \\
\hline \#7 & $N E F M$ & $\begin{array}{l}\text { Neurofilament, } \\
\text { medium } \\
\text { polypeptide }\end{array}$ & $8 \mathrm{p} 21$ & Exon 1 \\
\hline \#8 & $P M F 1$ & $\begin{array}{l}\text { Polyamine- } \\
\text { modulated } \\
\text { factor } 1\end{array}$ & $1 \mathrm{q} 22$ & Intron 1 \\
\hline \#9 & $B D N F$ & $\begin{array}{l}\text { Brain-derived } \\
\text { neurotrophic } \\
\text { factor }\end{array}$ & $11 \mathrm{p} 14.1$ & Intron 1 \\
\hline$\# 10$ & SSTR5 & $\begin{array}{l}\text { Somatostatin } \\
\text { receptor } 5\end{array}$ & $16 \mathrm{p} 13.3$ & Promoter \\
\hline \#11 & $M Y O 1 D$ & Myosin ID & $17 q 11.2$ & Intron 1 \\
\hline$\# 12$ & $C A M K 2 N 2$ & $\begin{array}{l}\text { Calcium/ } \\
\text { calmodulin- } \\
\text { dependent } \\
\text { protein kinase } \\
\text { II inhibitor } 2\end{array}$ & $3 q 27.1$ & Promoter \\
\hline \#13 & GATA4 & $\begin{array}{l}\text { GATA binding } \\
\text { protein } 4\end{array}$ & $8 \mathrm{p} 23.1$ & Promoter \\
\hline \#14 & NFATC1 & $\begin{array}{l}\text { Nuclear factor of } \\
\text { activated } \\
\text { T-cells, } \\
\text { cytoplasmic, } \\
\text { calcineurin- } \\
\text { dependent } 1\end{array}$ & $18 \mathrm{q} 23$ & Promoter \\
\hline$\# 15$ & $A N K R D 9$ & $\begin{array}{l}\text { Ankyrin repeat } \\
\text { domain } 9\end{array}$ & $14 q 32.31$ & Exon 1 \\
\hline
\end{tabular}

CGI CpG island, MeDIP methylated DNA immunoprecipitation 


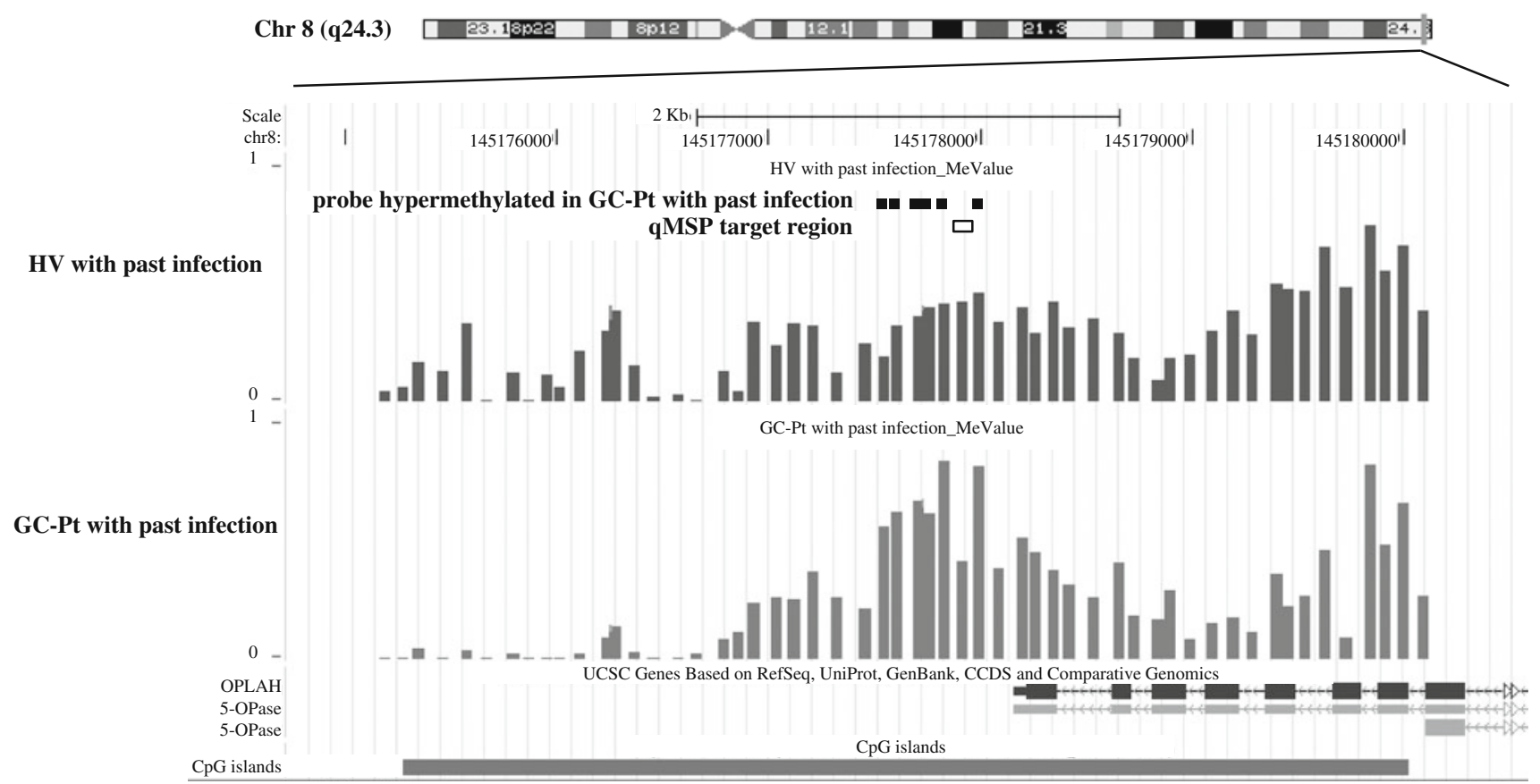

Fig. 1 Data of methylated DNA immunoprecipitation-CpG island (MeDIP-CGI) microarray analysis in the genomic region around CGI \#5. Methylation levels were assessed by Me values, and the Me values of the two pools were visualized by the UCSC Genome Browser (http://genome.ucsc.edu/) for a genomic region (from nt. $145,174,733$ to nt. $145,180,586$ on chromosome 8 in NCBI36/hg 18

levels in GC-Pt than in $\mathrm{HV}(P<0.05)$. Relative positions against a gene also varied-two CGIs being located in exon 1, two in intron 1, two $300 \mathrm{bp}$ downstream of the annotated end, and one overlapping with pre-microRNA 663.

Validation of the usefulness of the seven markers

The usefulness of the seven CGIs was validated by qMSP analysis of an independent set of samples (Fig. 2). The validation set consisted of seven never-infected HV (Group [G] 1), $21 \mathrm{HV}$ with current infection (G2), $14 \mathrm{HV}$ with past infection (G3), 21 GC-Pt with current infection (G4), and 21 GC-Pt with past infection (G5) (Supplementary Table 3). For comparison, two currently available markers ( $F L N c$ and THBD) were also analyzed. In the individuals with past infection (G3 and G5), the seven CGIs had levels that were 2.8-, 1.5-, 3.8-, 2.3-, 2.5-, 1.8-, and 3.8-fold, respectively, higher in G5 than in G3 $(P<0.01)$. FLNc tended to have a higher level in G5 than in G3 $(P=0.087)$, but $T H B D$ did not show any significant difference $(P=0.341)$. These data showed that the methylation levels of all the seven CGIs had the power of cancer risk estimation even in individuals with past infection. assembly). Vertical bars show Me values of individual probes. Closed boxes above the Me values indicate the differentially methylated probes. Quantitative methylation-specific polymerase chain reaction $(q M S P)$ primers were designed in the area shown by the open box. HV healthy volunteers, $G C-P t$ gastric cancer patients

In the $\mathrm{HV}$, methylation levels in $\mathrm{G} 2$ were much higher than those in G1 $(P<0.05)$, but those in G3 were lower than those in G2. This observation supported the model that active infection by $H$. pylori induces methylation potently in non-stem cells, in addition to stem cells, and that methylation levels will eventually decrease after $H$. pylori infection has been eradicated. Also, methylation levels in G3 were significantly higher (four of the seven CGIs, $P<0.05$ ) or tended to be higher than those in G1. This observation again supported the model that methylation induced in stem cells will remain even after $H$. pylori infection is eradicated.

Power of the seven CGIs as gastric cancer risk markers

AUCs to detect individuals in G5 were calculated using individuals in G3 and G5 (Table 2; Fig. 3). AUCs for the seven CGIs ranged between 0.78 and 0.84 and were significantly larger than $0.5(P<0.01)$. In contrast, the AUCs for the two currently available markers were 0.69 (95\% CI $0.51-0.87)$ and 0.65 (95\% CI 0.45-0.84), respectively, and were not significantly different from 0.5 . Using optimal cut-off values obtained by the ROCs, ORs for the seven CGIs were calculated to be 12.7-36.0 (Table 2). ORs for 

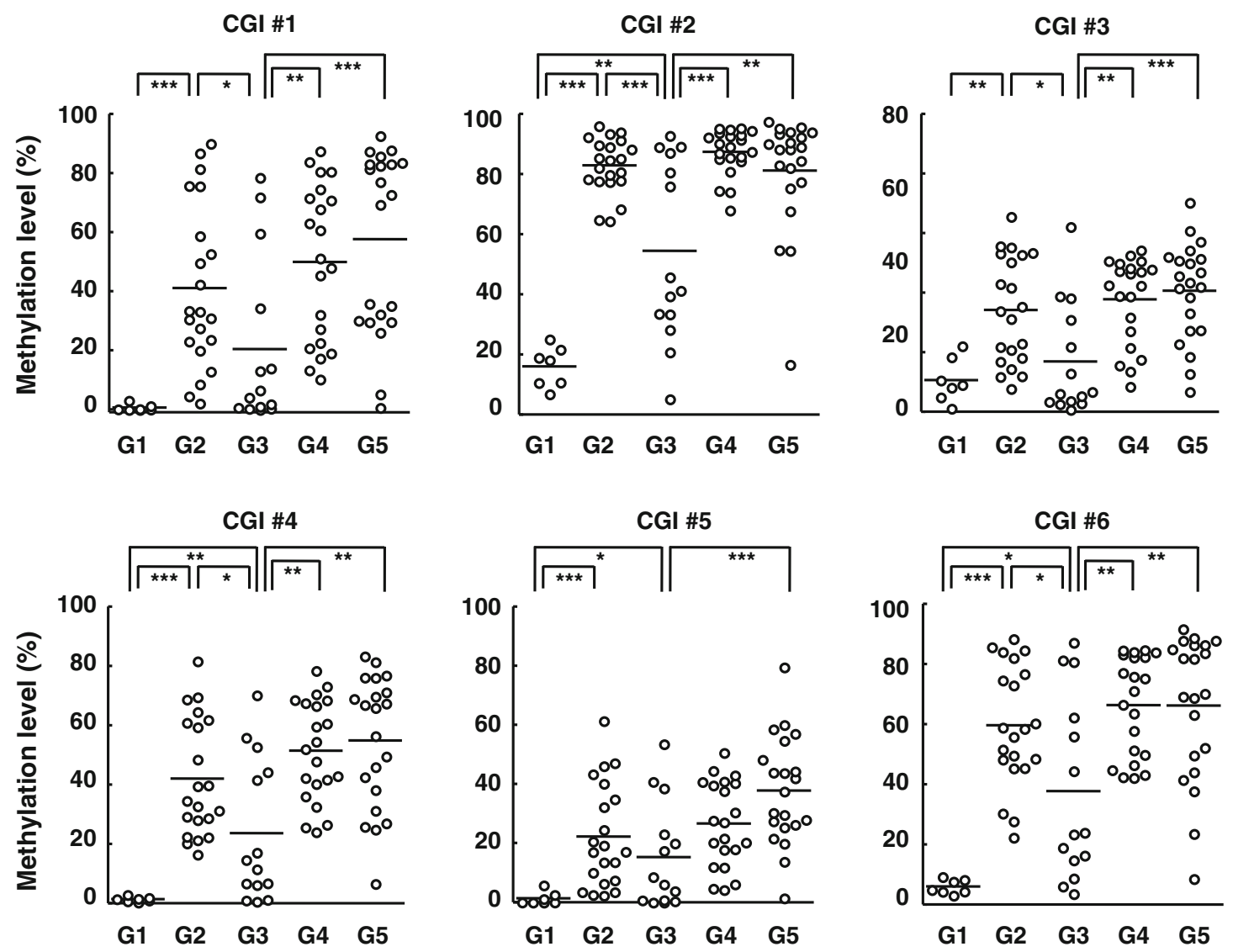

CGI \#7

FLNc

THBD
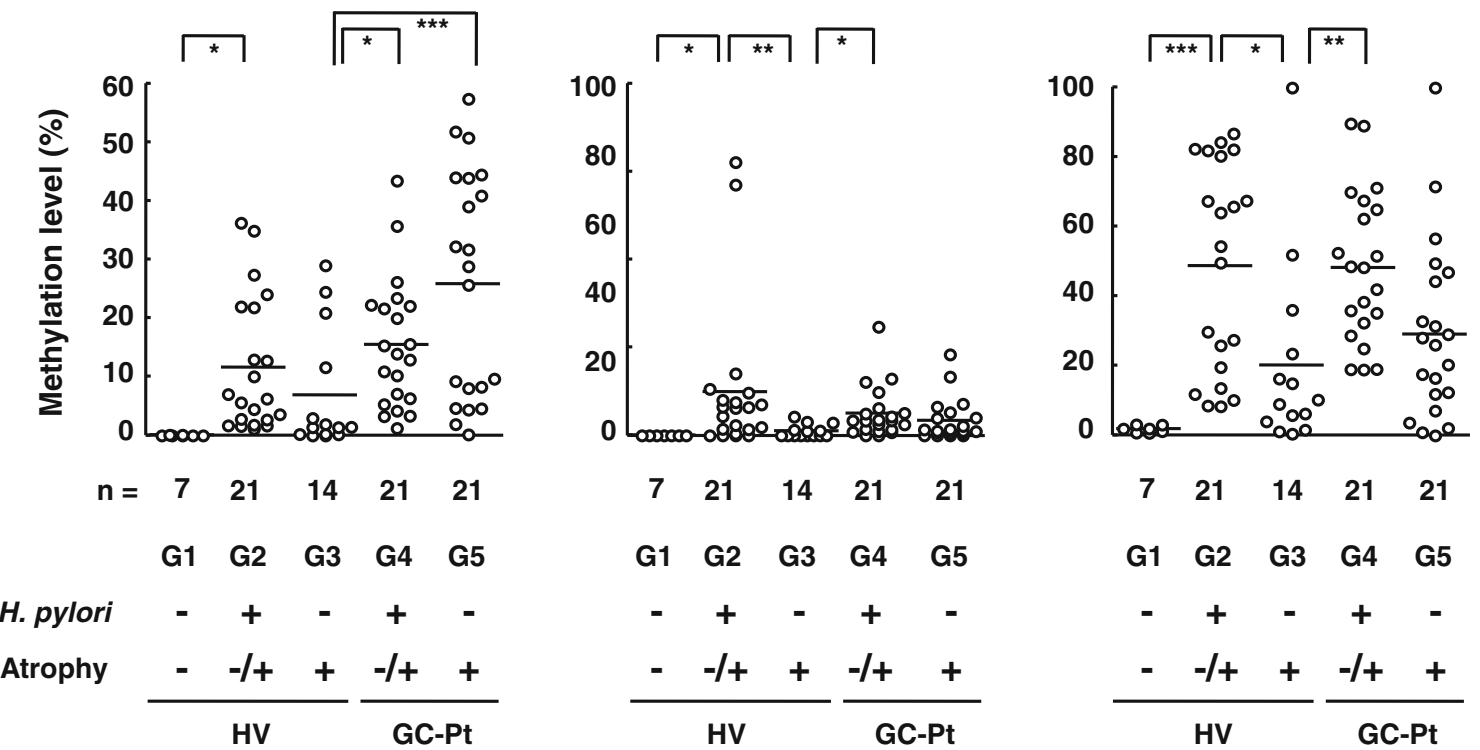

Fig. 2 Methylation levels of the seven CGIs and two currently available markers, $F L N C$ and $T H B D$, in the validation set. The horizontal line represents the mean methylation level in each group. Methylation levels of the seven CGIs in Group 5 (G5) were significantly higher than those in G3 $(P<0.01)$, but there were no significant differences for the two currently available markers. $* P<0.05, * * P<0.01, * * * P<0.001$ 
Table 2 AUC and OR for new and currently available markers

$C G I \mathrm{CpG}$ island, $A U C$ area under the curve, $C I$ confidence interval, $O R$ odds ratio

\begin{tabular}{llllrlrr}
\hline CGI no. & Gene symbol & AUC & 95\% CI & $P$ value & OR & $95 \%$ CI & $P$ value \\
\hline$\# 1$ & EMX1 & 0.84 & $0.70-0.97$ & $<0.001$ & 23.8 & $3.7-153$ & $<0.001$ \\
$\# 2$ & miR663 & 0.78 & $0.62-0.94$ & 0.006 & 26.7 & $2.8-258$ & 0.005 \\
$\# 3$ & NKX6-1 & 0.84 & $0.69-0.99$ & $<0.001$ & 15.0 & $2.8-80.1$ & 0.002 \\
$\# 4$ & OTP & 0.83 & $0.69-0.97$ & 0.001 & 36.0 & $3.7-354$ & 0.002 \\
$\# 5$ & OPLAH & 0.83 & $0.69-0.98$ & 0.001 & 15.6 & $2.9-83.5$ & 0.001 \\
$\# 6$ & CYP1B1 & 0.78 & $0.62-0.94$ & 0.006 & 12.7 & $2.1-76.7$ & 0.006 \\
$\# 7$ & NEFM & 0.84 & $0.71-0.98$ & $<0.001$ & 23.8 & $3.7-153$ & $<0.001$ \\
- & FLNC & 0.69 & $0.51-0.87$ & 0.055 & 5.7 & $1.2-25.9$ & 0.025 \\
- & THBD & 0.65 & $0.45-0.84$ & 0.152 & 5.0 & $1.1-21.8$ & 0.032 \\
\hline
\end{tabular}

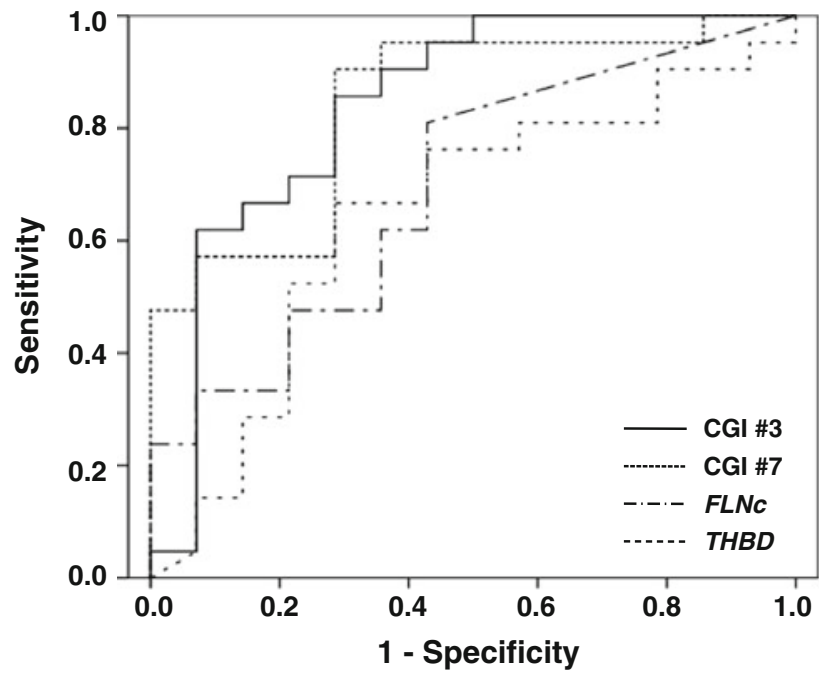

Fig. 3 Receiver-operating characteristic (ROC) curves of CGI \#3 and $\# 7$, whose AUC values were the largest in the seven CGIs, are shown with those of two currently available markers, FLNC and THBD. Black line, dotted line, dot-and-dash line, and dashed line show ROC curves of CGI \#3, \#7, FLNc, and THBD, respectively. The AUC values of CGI \#3 and \#7 were larger than those of FLNC and THBD

the two currently available markers, $F L N c$ and $T H B D$, were 5.7 (95\% CI 1.2-25.9) and 5.0 (95\% CI 1.1-21.8), respectively. These results clearly showed that the methylation levels of the seven CGIs had greater power than the two currently available markers to estimate gastric cancer risk in individuals with past infection.

\section{Discussion}

In the present study, by carrying out genome-wide methylation analysis of gastric cancer patients (GC-Pt) and healthy volunteers (HV), both with past infection, we screened seven gastric cancer risk markers that are highly informative in individuals with past infection. Their usefulness was validated in 35 individuals (21 GC-Pt and 14 age-matched HV). To our knowledge, this is the first study that has evaluated epigenetic gastric cancer risk markers in individuals with past infection, and these markers are expected to be especially useful. This is because the number of individuals with past infection is increasing as more and more people receive $H$. pylori eradication therapy [18], but the usefulness of the current methods for gastric cancer risk estimation, i.e., a combination of the detection of $H$. pylori infection and the serum pepsinogen test, in this population has not been established [18-20].

None of the seven CGIs were located in promoter regions. We analyzed the association between the methylation levels of the seven CGIs and the expression levels of genes close to them, but no association was observed for any of the seven CGIs (data not shown). This was in line with the current knowledge that DNA methylation of only promoter CGIs consistently causes gene silencing, but that methylation of gene bodies may or may not be associated with increased expression [14, 21, 22]. The lack of association between methylation and gene expression supported the hypothesis that the methylation of these seven CGIs reflects the degree of overall epigenomic damage in gastric stem cells, and that the degree of epigenomic damage, and not the change of expression of individual genes, is associated with gastric cancer risk.

Epigenomic damage induced by $H$. pylori infection is one of the major causes of gastric cancer [23-26], but it is not known whether the epigenomic damage is independent of other risk factors. For example, salt intake is a risk factor for gastric cancer [27, 28], and although it does not induce methylation in gastric mucosae by itself in a Mongolian gerbil model [29, 30], it shows synergistic effects with H. pylori on cancer development [31]. It is not known yet whether epigenomic damage in the gastric mucosa provides independent information from past salt exposure or whether the exposure is already reflected in methylation levels. Multivariate analysis in a large cohort with a reliable record of history of salt intake will clarify this issue, and might provide a risk marker that complements the epigenetic gastric cancer risk markers.

In conclusion, we identified seven CGIs whose methylation levels are increased after $H$. pylori infection, and 
are associated with gastric cancer risk even in individuals with past infection. These seven CGIs are promising candidate markers to estimate gastric cancer risk.

Acknowledgments This study was supported by Grants-in-Aid for Pioneering Basic Research and for the Third-term Comprehensive Cancer Control Strategy from the Ministry of Health, Labour and Welfare, Japan.

\section{References}

1. Uemura N, Okamoto S, Yamamoto S, Matsumura N, Yamaguchi $\mathrm{S}$, Yamakido M, et al. Helicobacter pylori infection and the development of gastric cancer. N Engl J Med. 2001;345:784-9.

2. Forman D, Webb P, Parsonnet J. H. pylori and gastric cancer. Lancet. 1994;343:243-4.

3. Suzuki H, Iwasaki E, Hibi T. Helicobacter pylori and gastric cancer. Gastric Cancer. 2009;12:79-87.

4. Ekström AM, Held M, Hansson LE, Engstrand L, Nyrén O. Helicobacter pylori in gastric cancer established by $\mathrm{CagA}$ immunoblot as a marker of past infection. Gastroenterology. 2001;121:784-91.

5. El-Omar EM, Carrington M, Chow WH, McColl KE, Bream JH, Young HA, et al. Interleukin-1 polymorphisms associated with increased risk of gastric cancer. Nature. 2000;404:398-402.

6. Loh M, Koh KX, Yeo BH, Song CM, Chia KS, Zhu F, et al. Meta-analysis of genetic polymorphisms and gastric cancer risk: variability in associations according to race. Eur $\mathrm{J}$ Cancer. 2009;45:2562-8.

7. Maekita T, Nakazawa K, Mihara M, Nakajima T, Yanaoka K, Iguchi M, et al. High levels of aberrant DNA methylation in Helicobacter pylori-infected gastric mucosae and its possible association with gastric cancer risk. Clin Cancer Res. 2006;12:989-95.

8. Nakajima T, Enomoto S, Yamashita S, Ando T, Nakanishi Y, Nakazawa K, et al. Persistence of a component of DNA methylation in gastric mucosae after Helicobacter pylori eradication. J Gastroenterol. 2010;45:37-44.

9. Nakajima T, Maekita T, Oda I, Gotoda T, Yamamoto S, Umemura $\mathrm{S}$, et al. Higher methylation levels in gastric mucosae significantly correlate with higher risk of gastric cancers. Cancer Epidemiol Biomarkers Prev. 2006;15:2317-21.

10. Ushijima T. Epigenetic field for cancerization. J Biochem Mol Biol. 2007;40:142-50.

11. Japanese Gastric Cancer Association. Japanese classification of gastric carcinoma-2nd English edition. Gastric Cancer. 1998;1:10-24.

12. Asaka M, Sugiyama T, Nobuta A, Kato M, Takeda H, Graham DY. Atrophic gastritis and intestinal metaplasia in Japan: results of a large multicenter study. Helicobacter. 2001;6:294-9.

13. Ohkusa T, Fujiki K, Takashimizu I, Kumagai J, Tanizawa T, Eishi $\mathrm{Y}$, et al. Improvement in atrophic gastritis and intestinal metaplasia in patients in whom Helicobacter pylori was eradicated. Ann Intern Med. 2001;134:380-6.
14. Yamashita S, Hosoya K, Gyobu K, Takeshima H, Ushijima T. Development of a novel output value for quantitative assessment in methylated DNA immunoprecipitation-CpG island microarray analysis. DNA Res. 2009;16:275-86.

15. Takeshima H, Yamashita S, Shimazu T, Niwa T, Ushijima T. The presence of RNA polymerase II, active or stalled, predicts epigenetic fate of promoter CpG islands. Genome Res. 2009;16: 275-86.

16. Kaneda A, Kaminishi M, Sugimura T, Ushijima T. Decreased expression of the seven ARP $2 / 3$ complex genes in human gastric cancers. Cancer Lett. 2004;212:203-10.

17. Weisenberger DJ, Campan M, Long TI, Kim MJ, Woods C, Fiala $\mathrm{E}$, et al. Analysis of repetitive element DNA methylation by MethyLight. Nucleic Acids Res. 2005;33:6823-36.

18. Selgrad M, Bomschein J, Rokkas T, Malfertheiner P. Clinical aspects of gastric cancer and Helicobacter pylori-screening, prevention, and treatment. Helicobacter. 2010;15:40-5.

19. Kim N, Jung HC. The role of serum pepsinogen in the detection of gastric cancer. Gut Liver. 2010;4:307-19.

20. Mizuno S, Kobayashi M, Tomita S, Miki I, Masuda A, Onoyama $\mathrm{M}$, et al. Validation of the pepsinogen test method for gastric cancer screening using a follow-up study. Gastric Cancer. 2009;12:158-63.

21. Hellman A, Chess A. Gene body-specific methylation on the active X chromosome. Science. 2007;315:1141-3.

22. Rauch TA, Wu X, Zhong X, Riggs AD, Pfeifer GP. A human B cell methylome at 100-base pair resolution. Proc Natl Acad Sci USA. 2009; 106:671-8.

23. Rashid A, Issa JP. CpG island methylation in gastroenterologic neoplasia: a maturing field. Gastroenterology. 2004;127:1578-88.

24. Oue N, Motoshida J, Yokozaki H, Hayashi K, Tahara E, Taniyama K, et al. Distinct promoter hypermethylation of p16INK4a, $\mathrm{CDH} 1$, and RAR-beta in intestinal, diffuse-adherent, and diffusescattered type gastric carcinomas. J Pathol. 2002;198:55-9.

25. Shin CM, Kim N, Jung Y, Park JH, Kang GH, Kim JS, et al. Role of Helicobacter pylori infection in aberrant DNA methylation along multistep gastric carcinogenesis. Cancer Sci. 2011;101: 1337-46.

26. Suzuki H, Tokino T, Shinomura Y, Imai K, Toyota M. DNA methylation and cancer pathways in gastrointestinal tumors. Pharmacogenomics. 2008;9:1917-28.

27. World Cancer Research Fund/American Institute for Cancer Research. Food, nutrition, physical activity, and the prevention of cancer: a global perspective. Washington, DC: AICR. 2007.

28. Nutrition and the prevention of chronic diseases. World Health Organ Tech Rep Ser. 2003;916:1-149.

29. Hur K, Niwa T, Toyoda T, Tsukamoto T, Tatematsu M, Yang $\mathrm{HK}$, et al. Insufficient role of cell proliferation in aberrant DNA methylation induction and involvement of specific types of inflammation. Carcinogenesis. 2011;32:35-41.

30. Tatematsu M, Nozaki K, Tsukamoto T. Helicobacter pylori infection and gastric carcinogenesis in animal models. Gastric Cancer. 2003;6:1-7.

31. Nozaki K, Shimizu N, Inaba K, Tsukamoto T, Inoue M, Kumagai $\mathrm{T}$, et al. Synergistic promoting effects of Helicobacter pylori infection and high-salt diet on gastric carcinogenesis in Mongolian gerbils. Jpn J Cancer Res. 2002;93:1083-9. 